\title{
Audiological and electrophysiological assessment of professional orchestral musicians
}

\author{
Alessandra Giannella Samelli ${ }^{1}$ \\ https://orcid.org/0000-0002-7164-8942 \\ Camila Maia Rabelo' \\ https://orcid.org/0000-0001-5431-8071 \\ Liliane Aparecida Fagundes Silva ${ }^{1}$ \\ https://orcid.org/0000-0001-8985-0447 \\ Denise Gonzaga ${ }^{1}$ \\ https://orcid.org/0000-0002-9301-7340 \\ Joyce Miranda Santiago ${ }^{1}$ \\ https://orcid.org/0000-0002-6334-0147 \\ Fernanda Cristina Leite Magliaro' ${ }^{1}$ \\ https://orcid.org/0000-0003-0627-4320 \\ Carla Gentile Matas ${ }^{1}$ \\ https://orcid.org/0000-0002-9408-7172
}

Universidade de São Paulo, Faculdade de Medicina - FMUSP, Departamento de Fisioterapia, Fonoaudiologia e Terapia Ocupacional, São Paulo, São Paulo, Brasil.

This projected was carried out at the Departamento de Fisioterapia, Fonoaudiologia e Terapia Ocupacional da Faculdade de Medicina da Universidade de São Paulo - FMUSP - São Paulo, São Paulo, Brasil.

Research support source: Fundação de Amparo à Pesquisa do Estado de São Paulo - Fapesp under process number 2012/14267-6.

Conflict of interests: Nonexistent

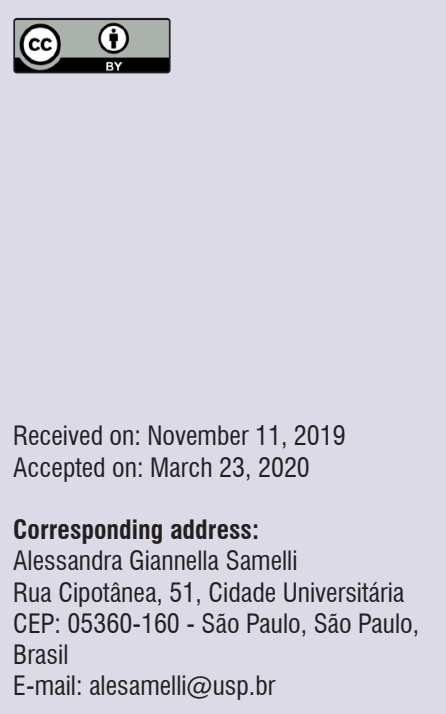

\section{ABSTRACT}

Purpose: to verify whether the frequent musical exposure can impair peripheral and central auditory pathway responses in professional orchestral musicians.

Methods: 45 male individuals from 19 to 40 years old participated in the study. They were divided into two groups: one comprising 30 orchestral musicians who played strings or wind instruments, and another with 15 nonmusicians. The two groups were submitted to both conventional and high-frequency pure-tone audiometry, transientevoked otoacoustic emissions, and frequency-following response. The results were subjected to descriptive and inferential statistical analysis, using the one-way ANOVA unmatched samples parametric test, with a $5 \%$ significance level.

Results: no significant differences were observed between the hearing thresholds in both conventional and high-frequency audiometry and frequency-following response. However, there were statistically significant differences between transient-evoked otoacoustic emission responses, with lower responses to musicians in comparison to the nonmusician group.

Conclusion: the results suggest that frequent musical exposure experienced by orchestral musicians can impair the cochlear hair cells' function. Therefore, audiological monitoring is important to detect subclinical impairments.

Keywords: Music; Hearing; Electrophysiology; Hearing Loss; Cochlea 


\section{INTRODUCTION}

The exposure to high sound pressure levels can cause auditory damage, leading to permanent hearing loss, besides other auditory symptoms as tinnitus and hyperacusis ${ }^{1,2}$.

Music, although considered different from the noise for its spectral characteristics, when played in high sound pressure levels with long periods of exposure, can progressively and permanently injure the auditory system ${ }^{1,3}$.

It is known that professional musicians constantly attend rehearsal and presentation environments, where the sound pressure levels surpass the intensity of $85 \mathrm{~dB}$ (A). Even though it is notorious that for jazz, pop and rock band musicians sound intensity is higher ${ }^{1,4,5}$ due to their use of amplification, research has been showing that the sound pressure levels reached in symphony orchestra presentations can range from 79 to $110 \mathrm{~dB}$ $(A)$, even reaching peaks of $115 \mathrm{~dB}(A)^{6}$. Furthermore, to ensure a pleasant instrument performance, the musicians need to spend many hours studying and presenting, hence characterized as a risk environment for the development of hearing loss in this population.

With this in mind, some studies have evaluated the auditory symptoms among musicians, and tinnitus has been a very common complaint, affecting more than $50 \%$ of the individuals ${ }^{2,7-9}$.

Moreover, other studies have evaluated orchestral musicians' hearing through conventional pure-tone audiometry, and the results showed that these individuals can present hearing loss through the years of exposure. In this sense, greater damage was observed for 4 to $8 \mathrm{~Hz}$ frequencies ${ }^{8,10,11}$. On the other hand, a study noted hearing thresholds lower than 20 $\mathrm{dB} H \mathrm{HL}$ in music students ${ }^{12}$.

It is known that cochlear impairment in its initial stage may not change pure-tone hearing thresholds in the conventional frequencies ${ }^{7}$. Thus, the auditory assessment through high-frequency audiometry (above $8 \mathrm{kHz}$ ), as well as transient-evoked otoacoustic emissions (TEOAE), is important to investigate whether there is cochlear impairment in this population.

The TEOAE responses are generated by the energy liberated from the cochlear outer hair cells, resulting from brief click stimulations ${ }^{13}$. When there are no middle ear pathologies, the absence or low TEOAE amplitude can indicate a cochlear dysfunction even before any relevant clinical evidence is perceived through pure-tone audiometry ${ }^{14}$. Some studies have observed that orchestral musicians can present diminished TEOAE response amplitude, and the longer the exposure to such music, the worse can the cochlear impairment be ${ }^{10,11}$.

Furthermore, to complement the battery of audiological examinations, the assessment of the auditory pathway's electrophysiological response is an important measure, as it can detect alterations throughout the auditory nerve to the brainstem ${ }^{15}$. The most employed acoustic stimulus to find such a measure is the click, because it triggers synchronic responses from a great number of neurons, representing a wide frequency range ${ }^{16}$. Despite this, the record generated by speech sounds through the frequency-following response (FFR) requires a synchronized neural response to be decoded; hence, it is an ideal method to study the neural basis of speech perception ${ }^{17}$.

Little is yet known about the influence exposure to music can have on symphony orchestra professional musicians' auditory pathway as a whole, since most of the studies involving musicians evaluate those of other musical genres, such as jazz, pop and rock. Moreover, they concentrate on assessing the peripheral portion of the auditory pathway.

Recently, studies have demonstrated that exposure to high sound pressure levels can cause damage to the auditory system, even when hearing thresholds measured through conventional audiometry are not lowered, due to a synaptopathy. Such alterations can lead to tinnitus, hyperacusis, and difficulties in speechin-noise perception ${ }^{18,19}$.

Therefore, it is essential to investigate whether there are auditory alterations in symphony orchestra musicians as well, considering both the conventional and high-frequencies hearing thresholds assessment, the cochlear function assessment, and the central auditory pathway functioning assessment. Hence, better guidance and hearing loss prevention programs can be offered to this population.

This study aimed at verifying whether frequent exposure to music can impair the responses of the central and peripheral auditory pathways in professional orchestral musicians.

\section{METHODS}

This is an observational cross-sectional study, approved by the Research Ethics Committee of the Faculdade de Medicina da Universidade de São Paulo - FMUSP, SP, Brazil, under process number 241/12. Before beginning the procedures, all the participants read and signed the Informed Consent Form. 
A total of 45 individuals from 19 to 40 years old participated in this study. They were divided into two groups: the control group comprising nonmusicians (NMG), and the study group with professional orchestral musicians (MG), whose instruments had to be either strings or wind ones.

The inclusion criteria for the MG were: being a professional musician; being a member of an orchestra for over two years; being exposed to music at least once a week.

Regarding the exclusion criteria, these were the ones defined: reporting acoustic trauma; being exposed to occupational noise other than music; having a history of recurrent otitis media; having a previous history of otologic surgery; having conductive hearing loss or excessive cerumen in the external acoustic meatus.

The inclusion criterion for the NMG was the absence of professional-level exposure to music; as for the exclusion criteria, they were the same as those of the MG.

Hence, the MG comprised 30 male professional musicians, whose ages ranged from 19 to 36 years (22.25 \pm 4.08); and the NMG comprised 15 male individuals whose ages ranged from 20 to 40 years (a mean of $24.87 \pm 6.02$ ).

In the MG, the daily exposure to intense music sounds averaged 5.75 hours, and the average time of musical experience was 10.75 years. As for the type of instruments, 15 individuals played string ones, and 15 , wind ones; none of them used hearing protection devices when exposed to music.

To characterize the rehearsal environment, the sound pressure levels were measured during two rehearsals in different days, with the Svantek's ${ }^{\text {TM }}$ SV 102 equipment, configured to A-weighting, low response, maximum daily exposure (8 hours) of $85 \mathrm{~dB}(\mathrm{~A})$, exchange rate equal to $5 \mathrm{~dB}$. The dosimeter was placed ahead of and behind the orchestra, with a measuring time of 180 minutes. The measures observed ranged from 74.1 to $103.2 \mathrm{~dB}(\mathrm{~A})$, with mean Leq of $87.3 \mathrm{~dB}$ (A).

Concerning the procedures in this research, all the participants filled out a questionnaire on their age, gender, schooling, previous medical and occupational history, and musical activities such as daily rehearsing time, sound intensity level, weekly participation in musical activities, type of instrument played, and use of hearing protection device.

The auditory assessment first included otoscopy, and then all the participants were submitted to acoustic immittance measuring to dismiss any conductive impairment and select the candidates based on the exclusion criteria. Thus, the normality criteria were the presence of a type-A tympanometric curve and ipsiand contralateral acoustic reflexes ${ }^{20}$.

Pure-tone hearing thresholds were assessed with the standard audiometry technique in an acoustically treated room using a clinical audiometer (Grason-Stadler's GSI 61). The hearing thresholds measured were for the conventional 0.25 to $8 \mathrm{kHz}$ frequencies, as well as the $9,10,12.5,14,16,18$ and $20 \mathrm{kHz}$ high frequencies. The hearing thresholds considered within limits of normality were those lower than $25 \mathrm{~dB} \mathrm{HL}^{21}$.

The transient-evoked otoacoustic emissions (TEOAE) were measured using an ILO 292 Plus OAE Analyzer, with nonlinear click stimulus at $80 \mathrm{~dB}$ SPL level. The present responses were considered when the signal-to-noise ratio was greater than $3 \mathrm{~dB}$ SPL. The participants were assessed in a sound booth inside a silent room.

The auditory electrophysiological assessment was conducted through the frequency-following response (FFR), using the Intelligent Hearing Systems' two-channel Smart EP. The procedure took place in an acoustically treated room with the participants comfortably seated in a reclining chair. They were instructed to gaze at an image placed approximately one and a half meter away from their eyes, to minimize eye movement.

For this assessment, their skin was cleaned with an abrasive paste. Then, the electrodes were fixed to the surface with conductive paste and microporous tape. The electrodes' positioning followed the international 10-20 standard: the reference electrode was fixed at $\mathrm{Fpz}$, the ground electrode on the forehead, and the active electrodes on the left and right mastoids (M1 and $\mathrm{M} 2$ ).

The stimulus used was the syllable /da/, lasting 40 $\mathrm{ms}$, in alternated polarity, monaurally presented at 80 $\mathrm{dBnHL}$, at a presenting rate of 11.1 stimuli per second, totaling 3,000 stimuli (three 1,000-stimulus sequences), presented through TDH-49 supra-aural earphones. The recording window lasted $60 \mathrm{~ms}, 150 \mathrm{~K}$ gain, 100 $\mathrm{Hz}$ high-pass and $3000 \mathrm{~Hz}$ low-pass filters. The three tracings obtained were selected and added, and in the resulting trace the $\mathrm{V}, \mathrm{A}, \mathrm{C}, \mathrm{D}, \mathrm{E}, \mathrm{F}$ and $\mathrm{O}$ waves were identified, which were analyzed regarding latency, using the normality offered by the Navigator-Pro ${ }^{22}$ equipment as the parameter. 
The results were submitted to statistical analysis. The quantitative data were evaluated through the mean value and standard deviation. For the inferential analysis, the one-way ANOVA non-matched sample parametric test was used. The significance level was set at $5 \%(p<0.05)$.

\section{RESULTS}

Initially, the difference in age between the groups was analyzed. They were homogeneous, with no statistically significant difference between them in this variable $(p$-value $=0.091$ )

The data collected in the anamneses showed that, regarding auditory symptoms, $55 \%$ of the musicians complained of tinnitus, $25 \%$ of an itchy ear, and $37 \%$ of earache. Moreover, $33.3 \%$ of the musicians complained of difficulties in speech-in-noise perception, and $60 \%$ of them complained of discomfort in the presence of intense sounds. None of the musicians reported using any hearing protection device in the rehearsals or presentations.

Concerning the audiological procedures, first, each ear's results were separately analyzed. Considering that the results obtained in the right and left ears had parallel responses and that there was no statistically significant difference between the ears ( $p$-value $>0.05$ ), the data were grouped. Hence, the results referring to the MG correspond to the data from 60 ears, whereas those of the NMG correspond to the data from 30 ears.

The results obtained in both evaluated groups revealed hearing thresholds for the conventional frequencies $(0.25$ to $8 \mathrm{kHz})$ within normality. When the audiometric results were compared, both for conventional pure-tone and high-frequency audiometry, no statistically significant differences were observed between the MG and NMG ( $p$-value > 0.05) (Tables 1 and 2).

Table 1. Comparison of the conventional pure-tone audiometry thresholds between both groups

\begin{tabular}{|c|c|c|c|c|}
\hline $\begin{array}{c}\text { Conventional pure-tone } \\
\text { audiometry }\end{array}$ & Group & Mean (dB HL) & Standard Deviation & p-value \\
\hline \multirow{2}{*}{$0.25 \mathrm{kHz}$} & NMG & 6.50 & 3.60 & \multirow{2}{*}{0.148} \\
\hline & $M G$ & 4.50 & 4.60 & \\
\hline \multirow{2}{*}{$0.5 \mathrm{kHz}$} & $N M G$ & 5.10 & 4.30 & \multirow{2}{*}{0.732} \\
\hline & $M G$ & 4.64 & 4.20 & \\
\hline \multirow{2}{*}{$1 \mathrm{kHz}$} & $N M G$ & 5.80 & 5.09 & \multirow{2}{*}{0.506} \\
\hline & $M G$ & 4.86 & 4.08 & \\
\hline \multirow{2}{*}{$2 \mathrm{kHz}$} & $N M G$ & 4.70 & 5.40 & \multirow{2}{*}{0.599} \\
\hline & $M G$ & 3.93 & 4.16 & \\
\hline \multirow{2}{*}{$3 \mathrm{kHz}$} & $N M G$ & 3.90 & 4.30 & \multirow{2}{*}{0.375} \\
\hline & $M G$ & 2.57 & 4.87 & \\
\hline \multirow{2}{*}{$4 \mathrm{kHz}$} & $N M G$ & 7.00 & 5.60 & \multirow{2}{*}{0.055} \\
\hline & $M G$ & 3.86 & 4.75 & \\
\hline \multirow{2}{*}{$6 \mathrm{kHz}$} & $N M G$ & 7.10 & 6.20 & \multirow{2}{*}{0.708} \\
\hline & $M G$ & 6.14 & 8.81 & \\
\hline \multirow{2}{*}{$8 \mathrm{kHz}$} & $N M G$ & 4.80 & 4.90 & \multirow{2}{*}{0.500} \\
\hline & $M G$ & 3.71 & 5.16 & \\
\hline
\end{tabular}

One-way ANOVA test

Legend: NMG-Nonmusicians group; MG-Musicians group; kHz- Kilohertz; dB HL: decibel hearing level 
Table 2. Comparison of the high-frequency pure-tone audiometry thresholds between both groups

\begin{tabular}{ccccc}
\hline $\begin{array}{c}\text { High-frequency pure- } \\
\text { tone audiometry }\end{array}$ & Group & Mean $(\mathbf{d B ~ H L})$ & Standard Deviation & p-value \\
\hline $9 \mathrm{kHz}$ & $\mathrm{NMG}$ & 9.6 & 5.8 & 0.213 \\
& $\mathrm{MG}$ & 7.07 & 6.57 & 0.452 \\
$10 \mathrm{kHz}$ & $\mathrm{NMG}$ & 8.7 & 7.3 & \\
& $\mathrm{MG}$ & 7 & 6.99 & 0.279 \\
$12.5 \mathrm{kHz}$ & $\mathrm{NMG}$ & 10.2 & 12.3 & \\
& $\mathrm{MG}$ & 7.21 & 6.12 & 0.332 \\
$14 \mathrm{kHz}$ & $\mathrm{NMG}$ & 70.7 & 15.8 & \\
& $\mathrm{MG}$ & 10.6 & 9.53 & 0.723 \\
$16 \mathrm{kHz}$ & $\mathrm{NMG}$ & 9.29 & 10.4 & \\
& $\mathrm{MG}$ & 10.3 & 12.17 & 0.930 \\
$18 \mathrm{kHz}$ & $\mathrm{NMG}$ & 10.56 & 9 & \\
& $\mathrm{MG}$ & 2 & 9.46 & 0.439 \\
\hline
\end{tabular}

One-way ANOVA test

Legend: NMG-Nonmusicians group; MG-Musicians group; kHz- Kilohertz; dB HL: decibel hearing level

The TEOAE results demonstrated statistically significant differences in all frequencies evaluated ( $p$-value $<0.05)$, with higher response amplitudes in the NMG. Only in the response parameter, despite the amplitude being higher in the NMG, the p-value did not reach the significance level adopted in this study ( $\mathrm{p}$-value $=$ 0.2447) (Table 3).
Regarding the FFR data, it was observed that the latency values for all waves were within normality standards in both groups. When comparing the results obtained between the groups, no statistically significant differences were observed ( $p$-value $>0.05$ ) (Table 4).

Table 3. Comparison of the transient-evoked otoacoustic emissions responses between the two assessed groups

\begin{tabular}{|c|c|c|c|c|}
\hline TEOAE & Group & Mean (dB SPL) & Standard Deviation & $\mathrm{p}$-value \\
\hline \multirow[b]{2}{*}{$1 \mathrm{kHz}$} & NMG & 13.62 & 7.55 & \multirow{2}{*}{$0.0038^{*}$} \\
\hline & $M G$ & 5.96 & 8.1 & \\
\hline \multirow{2}{*}{$1.5 \mathrm{kHz}$} & NMG & 20.16 & 5.73 & \multirow{2}{*}{$0.0000 *$} \\
\hline & $M G$ & 7.68 & 8.68 & \\
\hline \multirow{2}{*}{$2 \mathrm{kHz}$} & NMG & 19.62 & 4.86 & \multirow{2}{*}{0.0000 * } \\
\hline & MG & 7.84 & 7.55 & \\
\hline \multirow{2}{*}{$3 \mathrm{kHz}$} & NMG & 17.77 & 4.98 & \multirow{2}{*}{$0.0000^{*}$} \\
\hline & $M G$ & 6.61 & 6.61 & \\
\hline \multirow{2}{*}{$4 \mathrm{kHz}$} & NMG & 12.59 & 5.36 & \multirow[b]{2}{*}{$0.0000^{\star}$} \\
\hline & $M G$ & 2.55 & 7.2 & \\
\hline \multirow[b]{2}{*}{ Response } & $N M G$ & 13.41 & 3.12 & \multirow{2}{*}{0.2447} \\
\hline & $M G$ & 8.13 & 17.1 & \\
\hline
\end{tabular}

One-way ANOVA test

Legend: NMG-Nonmusicians group; MG-Musicians group; kHz- Kilohertz; dB SPL: decibel sound pressure level 
Table 4. Comparison of the Frequency Following Response wave latencies with speech stimulus between the two assessed groups

\begin{tabular}{|c|c|c|c|c|}
\hline FFR & Group & Mean (ms) & Standard Deviation & p-value \\
\hline \multirow{2}{*}{ V } & $\mathrm{NMG}$ & 6.61 & 0.66 & \multirow{2}{*}{1.000} \\
\hline & $M G$ & 6.61 & 0.78 & \\
\hline \multirow{2}{*}{ A } & NMG & 7.95 & 0.56 & \multirow{2}{*}{0.605} \\
\hline & $M G$ & 8.08 & 0.88 & \\
\hline \multirow{2}{*}{ C } & $N M G$ & 18.17 & 0.79 & \multirow{2}{*}{0.107} \\
\hline & $M G$ & 17.31 & 1.94 & \\
\hline \multirow{2}{*}{ D } & NMG & 22.93 & 1.19 & \multirow{2}{*}{0.775} \\
\hline & $M G$ & 23.03 & 1.06 & \\
\hline \multirow{2}{*}{$E$} & $N M G$ & 31.70 & 1.17 & \multirow{2}{*}{0.532} \\
\hline & $M G$ & 31.93 & 1.15 & \\
\hline \multirow{2}{*}{$\mathrm{F}$} & NMG & 40.03 & 1.68 & \multirow{2}{*}{0.668} \\
\hline & $M G$ & 39.87 & 0.82 & \\
\hline \multirow{2}{*}{0} & $N M G$ & 47.92 & 1.53 & \multirow{2}{*}{0.077} \\
\hline & $M G$ & 48.85 & 1.85 & \\
\hline
\end{tabular}

One-way ANOVA test

Legend: NMG-Nonmusicians group; MG-Musicians group; ms-milliseconds

\section{DISCUSSION}

This study enabled symphony orchestra musicians who played string and wind instruments to have their hearing evaluated. Their rehearsal environment was characterized in terms of sound pressure levels. Moreover, possible audibility differences these individuals might have were investigated in comparison with nonmusicians, given the musician's exposure to music in high sound pressure levels.

It was verified that the sound pressure levels during the orchestra rehearsals ranged from 74.1 to $103.2 \mathrm{~dB}$ (A), with mean Leq of $87.3 \mathrm{~dB}(\mathrm{~A})$. The values observed in this study are similar to those described in a literature review article ${ }^{6}$, which mentioned values ranging from 79 to $110 \mathrm{~dB}(\mathrm{~A})$ in symphony orchestra presentations.

Although the mean time of exposure (five hours) and the mean sound pressure level in the rehearsal environment (87.3 dB (A)) are within the safety limits recommended by the NR 15 regulatory norm $(85 \mathrm{~dB}(\mathrm{~A})$ for up to eight hours) ${ }^{23}$, it is known that every increase of $5 \mathrm{~dB}$ cuts by half the allowed exposure time limit. Thus, considering that the values measured reached $103 \mathrm{~dB}(\mathrm{~A})$, this population's risk of developing hearing loss cannot be dismissed.

In this study, none of the musicians reported using specialized personal protective equipment, which agrees with previous studies that observed that the use of hearing protection devices is not usually welcome among musicians ${ }^{7}$. Some authors commented that in the orchestras the difficulty in using personal hearing protection devices dwells in the need to listen to their own instrument, as well as the other musicians'. Furthermore, when the musical dynamic changed, it could be harder for the musicians to hear the lower sound intensity musical passages if they were wearing such protections; it would also be difficult for them to listen to the conductor during the rehearsals ${ }^{7}$.

In a study with five orchestras, it was observed that $94 \%$ of the participants were concerned about haring loss. However, only $20 \%$ of the participants who presented auditory complaints and $6 \%$ of those who did not present them used hearing protection devices. The author further stated that motivation and training are necessary to increase adherence to the use of hearing protection devices among musicians ${ }^{9}$. Similarly, another study conducted with orchestral musicians noted an adherence of only $2 \%$ in wearing hearing protection devices ${ }^{8}$. Hence, an educative program must be developed along with these professionals, to grow in them the awareness about their auditory risks, as well as the necessary use of hearing protection devices specially developed for musicians, which would interfere less with the dynamics of their daily activity and at the same time prevent the development of hearing losses.

Concerning the main auditory complaints, it was observed that $55 \%$ of the musicians presented tinnitus. This percentage is similar to that found in other studies, in which the prevalence of this symptom in $51 \%{ }^{8}$ and $53 \%^{24}$ of the musicians was noted. Likewise, 
tinnitus was mentioned as one of the main effects of excessive exposure to high-intensity music in São Paulo's Municipal Symphony Orchestra ${ }^{7}$. Moreover, in Laitinen's study, temporary tinnitus was the most common complaint, reported by $37 \%$ of the individuals, whereas permanent tinnitus was reported by $15 \%$ of the women and $18 \%$ of the men ${ }^{9}$.

A recently published systematic literature review observed prevalence of hearing loss - affecting mainly the 3 to $6 \mathrm{kHz}$ frequencies - in $32 \%$ of the professional classical musicians. This study also observed that tinnitus was the main audiological complaint, with a prevalence of $25.8 \%$ in pop-rock musicians and $26.5 \%$ in classical musicians ${ }^{2}$.

Regarding the other complaints, it was observed that $33.3 \%$ of the musicians reported difficulties in speechin-noise perception, and $60 \%$ of them complained of discomfort in the presence of intense sounds. This agrees with the study by DiStadio et al. ${ }^{2}$, which states that music, both as entertainment and as a profession, can not only cause hearing loss but also induce other auditory symptoms as tinnitus and hyperacusis.

Some studies have pointed out that prolonged noise exposure can change the ability to distinguish both speech and nonspeech sounds ${ }^{25,26}$. Other studies that assessed the comprehension of speech with background noise, with normal-hearing individuals comparing those exposed to noise with those that were not, concluded that the group of exposed individuals had fewer right answers, suggesting an impairment in speech intelligibility in situations of unfavorable listening, even with hearing thresholds within normality ${ }^{25,27}$. Comparing the findings of noiseexposed workers with those of the musicians assessed in this study, it can be suggested that, even though it is not noise, exposure to high-intensity music can have damaged speech-in-noise perception, which would explain the complaint reported by more than $30 \%$ of the musicians.

Analyzing the results of the conventional pure-tone audiometry, hearing thresholds within normality standards were observed in both groups. Moreover, in both conventional and high-frequency pure-tone audiometry, there were no statistically significant differences between the MG and the NMG.

This finding corroborates a study that did not observe differences between music and nonmusic students, whose hearing thresholds were lower than 20 $\mathrm{dB} H \mathrm{HL}$ in $83 \%$ of those evaluated in both groups ${ }^{12}$.
Another two studies that assessed orchestral musicians observed hearing thresholds within normality for the conventional frequencies, even after many years of exposure. Nonetheless, a notch in $6 \mathrm{kHz}$ frequency was noted, similar to that observed in noise-induced hearing loss 28,29 .

Unlike the findings in this study, PawlaczykŁuszczyńska et al. ${ }^{10}$ found audiograms typical of noise-induced hearing loss in $28 \%$ of the musicians assessed. Similarly, another study observed bilateral hearing loss in $19.2 \%$ of the musicians ${ }^{8}$. Yet another study observed that more than $50 \%$ of the symphony orchestra musicians presented sensorineural hearing loss, with higher thresholds in the higher frequencies, in both conventional and high-frequency audiometry ${ }^{24}$.

It should be highlighted that the individuals assessed in this study are from a young age group (mean of 22.25 years), different from the abovementioned studies, in which the mean age ranged from 35 to 44 years $8,10,24$. Another study observed thresholds lower than $15 \mathrm{~dB}$ $\mathrm{HL}$ in a group of musicians; however, it verified hearing thresholds higher than this intensity in 4 to $8 \mathrm{kHz}$ frequencies in individuals older than 40 years ${ }^{11}$. Hence, age seems to be one of the main factors causing the disagreement between the mentioned studies.

Some authors ${ }^{7}$ observed that pure-tone audiometry assessment can present normal results even when the individuals have some complaint, considering that normality in pure-tone audiometry thresholds in individuals with tinnitus is not a deciding factor to dismiss the possibility of cochlear impairment?

In this study, the TEOAE results revealed statistically significant differences between the groups for all frequencies assessed, with the MG presenting lower mean TEOAE responses in comparison with the NMG.

A study showed a decrease in the amplitude of TEOAE responses after the rehearsals, whose sound pressure level ranged from 75.6 to $83.1 \mathrm{~dB}^{11}$. Likewise, in another study that estimated the cumulative noise through the years - the calculation was based on the years of exposure and the measured sound pressure levels, with the musicians classified as either low-exposure or high-exposure -, a tendency to the statistical significance of high-exposure musicians presenting lower TEOAE responses was observed ${ }^{10}$. These data, combined with this study's findings, suggest that musical exposure can impair cochlear functioning, even when the hearing thresholds are within normality. 
Concerning central auditory pathway assessment through FFR, it was observed that all individuals presented results within the expected for normality, with no statistically significant differences between the groups.

A study that assessed the brainstem auditory electrophysiological responses in a group of professional rock/pop musicians verified that, although they presented lower hearing thresholds, as well as lower TEOAE amplitude, the brainstem auditory evoked potentials wave latencies were more precocious than those of nonmusicians. Based on these data, the authors suggested that musical training can make the acoustic signal be more easily transmitted through the auditory pathway ${ }^{30}$. It should be emphasized that the stimuli used in this study are different from those of the study mentioned, which can partly explain the differences in the findings.

Thus, this study's results can suggest that the injury caused by exposure to high sound pressure levels takes place first in the cochlear hair cells, and only later the impairment would manifest in the central pathways. Hence, changes in hearing thresholds in pure-tone audiometry and alterations in electrophysiological responses would only be noticed after a time of sound exposure longer than that experienced by the individuals in this study, given that auditory stimulation through musical training can make sounds be transmitted more easily, and so postpone the identification of any alteration in FFR wave latencies.

The lack of a legally established sound exposure standardization specific for musicians can lead people to falsely assume that this type of working environment is free of auditory risks. Therefore, attention is called to the need for implementing an auditory conservation program for this occupational group - one that establishes specific safety norms, considering the number of weekly workdays, the daily working hours, and the sound pressure levels allowed in each presentation.

Furthermore, it is recommended that they be made aware of the importance of using hearing protection devices during rehearsals and presentations, as well as undergoing audiological assessment and monitoring. This includes the TEOAE measures, considering that these responses have been proving capable of reflecting subclinical findings, as the early-stage cochlear impairment, which cannot yet be detected through pure-tone threshold auditory.

\section{CONCLUSION}

The results suggest that the frequent musical exposure experienced by orchestral musicians can damage the cochlear hair cells' function. Thus, audiological monitoring is important, so as to detect subclinical alterations.

\section{REFERENCES}

1. Juman S, Karmody CS, Simeon D. Hearing loss in steelband musicians. Otolaryngol Head Neck Surg. 2004;131(4):461-5.

2. Di Stadio A, Dipietro L, Ricci G, Della-Volpe A, Minni A, Greco A et al. Hearing loss, tinnitus, hyperacusis, and diplacusis in professional musicians: a systematic review. Int J Environ Res Public Health. 2018;15(10):pii: E2120.

3. Jacukowicz A, Wężyk A. Musculoskeletal, hearing and skin problems related to playing the instrument. Med Pr. 2018;69(4):383-94.

4. Kaharit K, Zachau G, Eklof M, Sandsjo L, Moller C. Assessment of hearing and hearing disorders in rock/jazz musicians. Int J Audiol. 2003;42(5):279-88.

5. Schmuziger N, Patscheke J, Probst R. Hearing in nonprofessional pop/rock musicians. Ear Hear. 2006;27(4):321-30.

6. Mendes MH, Morata TC. Exposição profissional à música: uma revisão. Rev. soc. bras. fonoaudiol. 2007;12(1):63-9.

7. Namuur FABM, Fukuda Y, Onishi ET, Toledo RN. Avaliação auditiva em músicos da Orquestra Sinfônica Municipal de São Paulo. Rev Bras Otorrinolaringol. 1999;65(5):390-5.

8. Pouryaghoub G, Mehrdad R, Pourhosein S. Noise-Induced hearing loss among professional musicians. J Occup Health. 2017;59(1):33-7.

9. Laitinen $\mathrm{H}$. Factors affecting the use of hearing protectors among classical music players. Noise Health. 2005;7(26):21-9.

10. Pawlaczyk-Łuszczyńska M, Dudarewicz A, Zamojska M, Śliwińska-Kowalska M. Hearing ability in orchestral musicians. Arch Acoust. 2010;35(4):579-94.

11. Dudarewicz A, Pawlaczyk-Łuszczyńska M, Zamojska-Daniszewska M, Zaborowski K. Exposure to excessive sounds during orchestra rehearsals and temporary hearing changes in hearing among musicians. Med Pr. 2015;66(4):479-86.

12. Pawlaczyk-Łuszczyńska M, Zamojska-Daniszewska M, Dudarewicz A, Zaborowski K. Exposure to 
excessive sounds and hearing status in academic classical music students. Int J Occup Med Environ Health. 2017;30(1):55-75.

13. Kemp DT, Ryan S, Bray P. A guide to the effective use of otoacoustic emissions. Ear Hear. 1990;11(2):93-105.

14. Henning RL, Bobholz K. Distortion product otoacoustic emissions in college music majors and nonmusic majors. Noise Health. 2016;18(80):10-20.

15. Matas CG, Neves IF. Potenciais evocados auditivos de curta latência. In: Fernandes FDM, Mendes BCA, Navas ALPGP (orgs). Tratado de Fonoaudilogia. $2^{\underline{a}}$ ed. São Paulo: Roca; 2009. p. 85-98.

16. Matas CG. Audiometria de tronco cerebral. In: Carvallo RMM (org). Fonoaudiologia: informação para a formação - procedimento em Audiologia. São Paulo: Guanabara Koogan; 2003. p. 43-56.

17. Kraus N, Nicol T. The musician's auditory world. Acoustics Today. 2010;6(3):15-27.

18. Kujawa SG, Liberman MC. Synaptopathy in the noise-exposed and aging cochlea: Primary neural degeneration in acquired sensorineural hearing loss. Hear Res. 2015;330(Pt B):191-9.

19. Eggermont JJ. Effects of long-term non-traumatic noise exposure on the adult central auditory system. Hearing problems without hearing loss. Hear Res. 2017;352:12-22.

20. Jerger J. Clinical experience with impedance audiometry. Arch Otolaryngol. 1970;92(4):311-24.

21. Lloyd LL, Kaplan H. Audiometric interpretation: a manual of basic audiometry. University Park Press: Baltimore; 1978.

22. Skoe E, Krizman J, Anderson S, Kraus N. Stability and plasticity of auditory brainstem function across the lifespan. Cereb Cortex. 2015;25(6):1415-26.

23. Norma Regulamentadora NR-15 - Atividades e Operações Insalubres - ANEXO I: Limites de tolerância para ruído contínuo ou intermitente, Portaria n. 3.214, de 8 de junho de 1978. Diário Oficial da União, 6 jul. 1978a.

24. Lüders D, Gonçalves CGO, Lacerda ABM, Schettini SRL, Silva LSG, Albizu EJ et al. Hearing and quality of life in musicians of a symphony orchestra. Audiol. Commun. Res. 2016;21:e1688.

25. Kujala T, Shtyrov Y, Winkler I, Saher M, Tervaniemi $M$, Sallinen $M$ et al. Long-term exposure to noise impairs cortical sound processing and attention control. Psychophysiology. 2004;41(6):875-81.

26. Massa CG, Rabelo CM, Moreira RR, Matas CG, Schochat E, Samelli AG. P300 in workers exposed to occupational noise. Braz J Otorhinolaryngol. 2012;78(6):107-12.

27. Kumar UA, Ameenudin S, Sangamanatha AV. Temporal and speech processing skills in normal hearing individuals exposed to occupational noise. Noise Health. 2012;14(58):100-5.

28. Kahari KR, Axelsson A, Hellstrom P, Zachau G. Hearing assessment of classical orchestral musicians. Scand Audiol. 2001a;30(1):13-23.

29. Kahari KR, Axelsson A, Hellstrom PA, Zachau G. Hearing development in classical orchestral musicians. A follow-up study. Scand Audiol. 2001b;30(3):141-9.

30. Samelli AG, Matas CG, Carvallo RM, Gomes RF, Beija CS, Magliaro FC et al. Audiological and electrophysiological assessment of professional pop/rock musicians. Noise Health. 2012;14(56):6-12. 